\title{
A Pilot Evaluation of a Rapid Screening Test for Nosocomial Meningitis or Pneumonia at a Neurosurgical Intensive Care Unit in Sweden
}

\section{Amir Ramezani}

Division of neuro and inflammation science,Departement of clinical and experimental medicine,linköping university,department ofneurosurgery,anesthetics operations and specialty surgery center

\section{Roya Darbani}

Department of dental research, malmö university,sweden

\section{Lars Eng}

the institute for protein eniromental affinity surveys,PEAS institute,linköping

Johanna Lönn

departement of dental research,malmö university,sweden

\section{lan yin}

the institute for protein enviromental affınity surveys,PEAS institute,linköping,sweden

\section{Annette Theodorsson}

division of neuro and inflammation science, Departement of clinical and experimental meicine, linköping university, Department of Neurosurgery, Anesthetics Operatins and specialty surgery center,sweden

\section{Fariba Nayeri ( $\sim$ fariba.nayeri@liu.se)}

The Institute for Protein Environmental Affinity Surveys; PEAS Institute https://orcid.org/0000-00032425-1018

\section{Research article}

Keywords: Neutrophil extracellular trap, Meningitis, neurosurgery intensive care, fever, point of care, ventilator-associated pneumonia, screening test, diagnosis.

Posted Date: August 20th, 2019

DOI: https://doi.org/10.21203/rs.2.13260/v1

License: (9) This work is licensed under a Creative Commons Attribution 4.0 International License. Read Full License 


\section{Abstract}

Background When post-neurosurgery patients develop fever, there are no convenient methods to immediately indicate the site of infection. The choice of empirical antibiotic therapy is evidently different in nosocomial meningitis compared to ventilator-associated pneumonia or urinary tract infection. Conventional bacterial cultures have a risk of being false negative due to antibiotic prophylaxis, and direct microscopic analysis of cerebrospinal fluid from such patients has limited diagnostic value. Due to the substantial mortality associated with nosocomial meningitis, broad spectrum antibiotics in high dosage are therefore commonly administered. Neutrophils as innate immunity system, trap and kill bacteria by neutrophil extracellular traps (NETs). NETs is composed of extracellular DNA and is released in cerebrospinal fluid during bacterial meningitis. Using a combination of sulphated-glycosaminoglycan and aniline dyes a platform was developed that reacted to extracellular host DNA and changed color within one minute in proportion to the amount of NETs in body fluid. This present study aimed to evaluate the sensitivity and specificity of the index strip test in identifying the site of infection. Methods Between November 2015 and November 2017, cerebrospinal fluid, bronchoalveolar fluid, and urine were collected on Mondays and Thursdays from the patients during the course of management (199 samples from 117 cases). The rapid strip test (1 minute) was used for simultaneous analysis of the fresh samples. The final diagnosis was settled at discharge. Results A total of 75 patients $(64 \%)$ had received empirical antibiotic therapy against nosocomial meningitis, while only 19 patients $(16 \%)$ had a verified diagnosis. The strip test could distinguish a verified meningitis $(n=19)$ with $89.5 \%$ sensitivity and $92.5 \%$ specificity. The test also identified ventilator-associated pneumonia $(n=32)$ with $93.8 \%$ sensitivity and $86.8 \%$ specificity. Conclusions The rapid strip test analyzed cerebrospinal and bronchoalveolar fluid from febrile patients post-neurosurgery and indicated the site of infection with clinically relevant sensitivity and specificity, indicating its potential to minimize the unnecessary use of antibiotics.

\section{Background}

An infection occurs when invading pathogenic microorganisms gain a foothold, succeed in growing, and thereby disturb the normal physiological properties of the tissue [1]. To minimize injuries, the microbe responsible for the infection must be identified, its susceptibility to antibiotics determined, and effective therapy initiated immediately [2]. The discovery and implementation of antibiotics is tremendously valuable in targeting specific pathogens, effectively eliminating them, and saving lives and resources [3]. However, sufficient guidelines and proper diagnostic instruments are not always available to communities to support proper antibiotics administration. Insufficient compliance regarding intake and unregulated administration has, in part, resulted in development of resistant bacterial strains [4]. Decreasing the consumption of antibiotics has a direct impact on reducing multidrug-resistant bacteria [5]. It is therefore urgent to develop screening tests for the early diagnosis of infections prior to the ultimate identification of the microorganism.

The diagnosis of nosocomial meningitis in patients who have undergone neurosurgical procedures is a substantial medical challenge [6], including its differential diagnosis from ventilator-associated 
pneumonia (VAP)[7]. The presence of an elevated number of leukocytes or red blood cells or a high level of lactate in the cerebrospinal fluid (CSF) of an injured brain is a suboptimal indicator of bacterial infections [8]. Furthermore, most postoperative neurosurgical patients receiving ventilator support have some degree of suspected infiltration/atelectasis on chest X-ray [9]. Bacteriuria is evidently common in catheterized patients [10].

Systemic inflammatory response markers such as C-reactive protein (CRP) and procalcitonin may or may not be elevated and do not indicate the site of infection[11].Conventional bacterial cultures have low sensitivity to detect an infection due to antibiotic prophylaxis in severe cases or to the fact that nosocomial infections are commonly caused by slow-growing opportunistic bacteria[12]. Furthermore, such infections do not induce CRP or procalcitonin elevation in all of the cases [13]. Therefore, irrespective of the routine analysis and culture results, broad-spectrum antibiotics to cover severe nosocomial meningitis are administered to patients that develop fever post-neurosurgery [6].

The local innate immunity system, which can be assessed based on activated neutrophils, can be used to develop rapid point-of-care tests [14]. Neutrophils are the immune system's first-line of defense against infection and have conventionally been thought to kill invading pathogens through two strategies: engulfment of microbes and secretion of anti-microbials. In 2004, a novel third function was identified: formation of neutrophil extracellular traps (NETs). NETs are networks of extracellular fibers, primarily composed of DNA from neutrophils, which bind pathogens [15]. NETs allow neutrophils to kill extracellular pathogens while minimizing damage to the host cells. Upon in vitro activation with the pharmacological agent phorbol myristate acetate (PMA), Interleukin 8 (IL-8) or lipopolysaccharide (LPS), neutrophils release granule proteins and chromatin to form an extracellular fibril matrix known as NETs through an active process [15]. NETs disarm pathogens with antimicrobial proteins such as neutrophil elastase, cathepsin G and histones that have a high affinity for DNA [16]. NETs provide for a high local concentration of antimicrobial components and bind, disarm, and kill microbes extracellularly independent of phagocytic uptake. In addition to their antimicrobial properties, NETs may serve as a physical barrier that prevents further spread of the pathogens. Furthermore, delivering the granule proteins into NETs may keep potentially injurious proteins like proteases from diffusing away and inducing damage in tissue adjacent to the site of inflammation [15-16].Vital NETosis can be stimulated by bacterial lipopolysaccharide (LPS), other bacterial products, TLR4-activated platelets, or complement proteins in tandem with TLR2 ligands [17]. Vital NETosis is made possible through the blebbing of the nucleus, resulting in a DNA-filled vesicle that is exocytosed and leaves the plasma membrane intact [17]. Its rapid formation and release does not result in neutrophil death, however, the cell is without DNA, raising questions about whether a cell without DNA can be considered alive. It has been noted that neutrophils can continue to phagocytose and kill microbes after vital NETosis, highlighting the neutrophil's anti-microbial versatility [18]. The ultrastructure of NETs is unusual; NETs consist of smooth filaments with a diameter of $\sim 17 \mathrm{~nm}$ [15], composed of stacked, and probably modified, nucleosomes [19]. 
NETosis is a form of "aggressive" neutrophil cell death that constrains and kills pathogens; in the end it is the physiological background of what has long been known as pus.

We recently assessed the ability of a strip test (index test) designed to detect locally produced substances including extracellular DNA extruded from activated neutrophils [20] to diagnose infection in body fluids. Metachromasia is a characteristic color change exhibited by certain aniline dyes upon binding to chromotropic substances [21] and this phenomenon has been widely used in histology. Methylene blue (O-Toluidine) is an excellent metachromatic dye that changes from blue to pink upon binding to highmolecular-weight polysaccharides, such as sulfated glycan [22]. Methylene blue binds to DNA/nucleotide with high affinity. Therefore, the pink dye will then quickly turn back to blue following addition of a proportional amount of oligo-nucleotide (inverted metachromasia). This present pilot study aimed to evaluate the sensitivity and specificity of the index test in identifying the site of infection. Left-over CSF, endotracheal secretion, and urine samples were consecutively collected from patients at a neurosurgical intensive care unit (ICU) and analyzed using a rapid strip test within a few hours after sampling.

\section{Methods}

Design: A pilot evaluation of a rapid screening test using left-over samples.

Setting: Neurosurgical intensive care unit at Linköping University Hospital, Sweden.

Subjects: Patients admitted to the neurosurgical intensive care unit.

Samples: As part of a routine procedure between November 2015 and November 2017, a total of 199 CSF samples were collected by nurses every Monday and Thursday from patients during their course of treatment at the neurosurgical ICU at Linköping University Hospital, Sweden. Endotracheal aspiration samples (ventilators, $n=73$ ) and urine samples (indwelling catheters, $n=71$ ) were collected from the patients when indicated. Due to agreement with the personnel, the study nurse transferred the samples into coded tubes. The study leader analyzed the samples using a strip test on the same day of sample collection and registered the results in an Excel database. The samples were subsequently kept frozen at $-135^{\circ} \mathrm{C}$. The patients were treated according to the guidelines of the clinic. The senior specialist at the Department of Infectious Diseases was consulted for each patient. Because such study was not performed previously, a pilot study was needed to evaluate the results and calculate the sample size for a prospective study. Therefore, the sample collection was paused in November 2017. During April-July 2018, patient journals were studied by project leader and information about age, sex, CSF cells and lactate, CRP, cultures from CSF, blood and endotracheal secretion, the chest X-ray, the antibiotic therapy, and the final diagnosis at discharge was registered for each case using the primary codes. The ethical committee of Linköping University Hospital approved this study (2010/284-32, 2015/429-32) and granted permission to collect the samples and document the unidentified cases by study leader. The study has been registered on clinicaltrials.gov (NCT03252028). 


\section{Index Test Analysis}

The strip tests (PEAS Institut, Linköping, Sweden article number 07350063630229, batch PKSR20151102, stability 2 years), used in this study were manufactured for R\&D purposes. They consisted of $0.5 \times 0.5 \mathrm{~cm}$ surfaces containing different levels of dextran sulfate and $o$-toluidine blue. Three or five such surfaces were attached to a plastic support $(0.5 \times 13 \mathrm{~cm})$, forming a strip. The testing procedure was as follows: the strip test was dipped in the sample for 5 seconds, and then removed and placed on its edge for 5 seconds on a tissue paper to remove excess liquid. The result was observed within 1, 10, and 20 minutes after the reaction, and the color change was compared with a color chart.

\section{Statistics}

The sensitivity, specificity, negative predictive value, and positive predictive value of the index test were calculated by Medcalc (https://www.medcalc.org/calc/diagnostic_test.php). Data from patients were used to evaluate differences between the results before and after therapy. In 19 patients with VAP, the results from the first and second test occasions were compared using the Wilcoxon matched-pairs signed-rank test. For post-hoc power analysis of data, a dichotomous endpoint, one-sample study design was used [23].

\section{Results}

\section{Empirical Antibiotic Therapy}

In total, 75 out of 117 patients (64\%) included in the study received empirical antibiotic therapy for suspected meningitis when signs of an infection with an unclear focus were observed. The therapy consisted of cefotaxime $3 \mathrm{~g}$ 3-4 times daily or meropenem $3 \mathrm{~g} 3$ times daily + vancomycin $1 \mathrm{~g}$ 2-3 times daily. In the rest of the cases, empirical antibiotic therapy for other nosocomial infections such as cefotaxime $1 \mathrm{~g} 3$ times daily or piperacillin/tazobactam $4 \mathrm{~g} 3$ times daily was initiated. In seven cases $(0.06 \%)$, no antibiotics were administered.

\section{Identified Groups}

Verified Central Nervous System Infection: Nineteen patients (total 30 samples, 8 females and 11 males, 1-87 years old, median age 62 years) had a verified central nervous system (CNS) infection. The samples were collected from CSF in which the cultures yielded growth of bacteria $(n=15)$ (Table 1, Fig. 1). Ten patients underwent neurosurgery due to shunt-related infection; in these patients, the preoperative cultures yielded growth of Staphylococcus aureus $(n=2)$, Propionibacterium acnes $(n=3)$, alpha-hemolytic streptococci $(\mathrm{n}=2)$, Staphylococcus epidermidis $(\mathrm{n}=2)$, and Enterobacter cloacae $(\mathrm{n}=1)$. In patients who underwent neurosurgery due to complications of meningitis, the preoperative cultures yielded growth of 
Streptococcus pneumoniae $(\mathrm{n}=3)$. Moreover, Escherichia coli $(\mathrm{n}=1)$ was cultured from subdural empyema. One patient suffered from brain toxoplasmosis $(n=1)$. Four cases developed CNS infection postneurosurgery. Cultures were negative in three cases (visible pus/turbid CSF), and sepsis and meningitis caused by Achromobacter spp. were found in one case. In seven cases, two to four samples on different occasions were collected.

CNS infection was not verified. Eighteen patients (total 32 samples, 6 females and 12 males, 41-85 years old, median age 61.5 years) had been treated as CNS infection. However, cultures from CSF did not yield growth of bacteria. (Fig. 1) (Supplementary material) [24].

Nosocomial Pneumonia: In total, 38 patients (17 females, 20-80 years old, median age 62 years) developed pneumonia post-neurosurgery. CSF samples were collected $(n=71)$ from these patients. The patients were on ventilators and developed fever, and the chest $X$-ray revealed infiltrates $(n=37)$. The cultures from endotracheal secretion revealed growth of bacteria $(n=24)$ (Table 2), and the CRP (range 5$491 \mathrm{mg} / \mathrm{mL}$, median $61 \mathrm{mg} / \mathrm{mL}$ ) and procalcitonin (range 0.1-14.0 $\mathrm{gg} / \mathrm{L}$, median $0.2 \mu \mathrm{g} / \mathrm{L}$ ) levels were elevated. Extra endotracheal secretion samples for index test analysis were available in 32 patients (total 57 samples) (Table 2). In 19 cases, two to six samples on different occasions were collected. This group showed significant differences between the index test results before and after antibiotic therapy (Fig. 2).

Other Postsurgical Infections: A total of 42 patients (total 66 samples, 16 females, 2-84 years old, median age 63 years) had postsurgical infections other than CNS infection or VAP. In this group, the CSF cultures yielded no growth, and no radiological evidence of pneumonia was seen (Fig. 1). Five patients experienced septicemia, and blood cultures yielded growth of Serratia marcescens $(n=1)$, coagulasenegative staphylococci $(\mathrm{n}=1)$, Enterococcus faecalis $(\mathrm{n}=1)$, Staphylococcus aureus $(\mathrm{n}=1)$, and Escherichia coli $(n=1)$.

\section{Validity of the Index Test to Identify the Focus of Infection}

CNS Infection: As the golden standard for diagnosing CNS infection, positive CSF cultures were used. In three cases, visible pus or turbid CSF confirmed a diagnosis of CNS infection $(n=19)$. Patients with nosocomial pneumonia + other infections (neither CNS infection nor VAP, $n=80$ ) were used as the control group. The index test identified a CNS infection with $89.5 \%$ sensitivity (95\% confidence interval [Cl] 66.998.7\%), 92.5\% specificity (95\% Cl 84.4-97.2\%), 97.4\% negative predictive value (95\% $\mathrm{Cl} 90.9-99.2 \%$ ), and $73.9 \%$ positive predictive value (95\% Cl 56.4-86.2\%). Accuracy was $91.9 \%$ (Table 3). 
In the patients that fulfilled therapy as bacterial meningitis without an objective evidence of meningitis $(n=18)$, the index test showed positive result with $66.6 \%$ sensitivity $(95 \% \mathrm{Cl} 40.9-86.6 \%), 92.5 \%$ specificity (95\% Cl 84.4-97.2\%), 92.5\% negative predictive value (95\% Cl 86.4-95.6\%) and 66.6\% positive predictive value (95\% Cl 46.4-82.1\%).

Nosocomial Pneumonia: Patients who fulfilled the criteria for nosocomial pneumonia $(n=32)$ were used as positive controls. The control group comprised patients with CNS infection + other infections (neither CNS infection nor VAP, $n=38$ ) in which the index test was performed on endotracheal secretion. Analysis revealed that the index test could distinguish pneumonia from other postsurgical infections with $93.8 \%$ sensitivity (95\% Cl 79.2-99.2\%), 86.8\% specificity (95\% Cl 71.9-95.6\%), 94.3\% negative predictive value (95\% Cl 81.1-98. 5\%), and 90\% positive predictive value (95\% Cl 80.5-95.9\%). Accuracy was $90.0 \%$ (Table 4).

The index test results for sputum differed significantly between samples taken at the first and second occasions $(P=0.0008)$. There were no significant differences in CRP $(P=0.4545)$, procalcitonin $(P=0.7995)$, or leukocyte particle concentration $(P=0.1353)$ levels between the first and second analyses (Supplementary material).

Urinary Tract Infection: In 23 patients, urine cultures yielded growth of the following bacteria: Pseudomonas aeruginosa $(\mathrm{n}=3)$, Escherichia coli $(\mathrm{n}=8)$, Enterococcus faecalis $(\mathrm{n}=5)$, Klebsiella pneumonia $(\mathrm{n}=2)$, Enterobacter cloacae $(\mathrm{n}=2)$, and extended-spectrum beta-lactamase producing bacteria $(n=1)$. Candida albicans was also found $(n=2)$. The index test was performed in 72 patients. The sensitivity of the strip test in urine samples collected from catheters was $78.6 \%$, specificity $55.2 \%$, negative predictive value $91.4 \%$, and positive predictive value $29.7 \%$.

\section{Post-Hoc Power Analysis}

Among the patients, $64 \%$ received empirical antibiotic therapy against nosocomial CNS infection, whereas $16 \%$ of patients had CNS infection. If the test could identify cases that should receive antibiotics successfully, the sample size with $95 \%$ power was 10 . The post-hoc power of the study was $99.9 \%$ (dichotomous endpoint, one-sample study [23].

\section{Discussion}

We investigated the sample size needed to evaluate an index test and identify the source of infection when there were no golden standards to distinguish fever caused by meningitis from nosocomial pneumonia or indwelling catheter-related urinary tract infection at an early stage. The index test identified 
nosocomial CNS infection by analysis of CSF and could diagnose nosocomial pneumonia by analysis of endotracheal secretion within 1 minute with an adequate power and accuracy.

Nosocomial bacterial meningitis may result from invasive procedures such as craniotomy, complicated head trauma, or metastatic infection in the course of bacteremia [6]. Bacterial meningitis, as a serious complication, occurs in $0.8-1.5 \%$ of patients who undergo craniotomy [25]. The incidence of meningitis associated with internal ventricular catheters, used for the treatment of hydrocephalus, ranges from $4 \%$ to $17 \%$ [25]. While that associated with external catheters is approximately $8 \%$ [26]. External lumbar catheters have been associated with meningitis rates of up to 5\% [27]. Meanwhile, the incidence of meningitis after head trauma is estimated to be 1.4\% [28]. Closed head trauma with basilar skull fracture is associated with up to $25 \%$ increased risk of infection [28]. Head trauma is the most common cause of recurrent bacterial meningitis [29]. Therefore, a clinical suspicion of nosocomial bacterial meningitis should prompt a diagnostic workup and antimicrobial therapy [6]. The workup consists of neuroimaging, CSF analysis (cell counts, Gram's staining, biochemical tests for glucose and protein, and cultures), and blood cultures [6]. The diagnosis of nosocomial bacterial meningitis is based on the results of CSF cultures. However, cultures require prolonged incubation, and results may be negative in patients who have received previous antimicrobial therapy [6]. Cell counts in CSF have low sensitivity and specificity and might be normal in patients in whom meningitis was confirmed by culture [8]. Moreover, pleocytosis is often observed in patients without positive cultures [8]. In patients subjected to neurosurgery, a lactate level $\geq 4 \mathrm{mmol} / \mathrm{L}$ in CSF showed a sensitivity of $88 \%$ and specificity of $98 \%$ to diagnose a postsurgical meningitis [30-31]. However, in bacterial meningitis associated with CSF shunts, the sensitivity of CSF lactate level was low [26]. Although, elevated levels of CRP and serum procalcitonin are suggestive of bacterial infection, they do not establish the diagnosis and the usefulness of these markers in the diagnosis of nosocomial bacterial meningitis has not been determined [11]. The British Society for Antimicrobial Chemotherapy recommends empirical therapy for all patients showing signs of postoperative meningitis. Treatment should be withdrawn after 72 hours if the results of CSF cultures are negative [24]. Thus, the patients in our pilot study in which, CSF cultures yielded no growth, the diagnosis of meningitis was not established and this group could not be used as appositive control group. However, patients who have received previous antimicrobial therapy may require treatment despite negative culture results [6]. The median antibiotic treatment duration for post-neurosurgical meningitis was reported to be 17-22.5 days [32]. The results of the present study showed that the index test could rule-out CNS infection with $97 \%$ negative predictive value and a significant reduce in antibiotic consumption is therefore, expected.

Nosocomial pneumonia is the most common cause of death among nosocomial infections and is the primary cause of death in ICUs [33]. Patients with risk factors or signs of clinical decompensation should have empirical therapy initiated at a lower threshold, and the therapy should be directed at a confirmed infection following positive culture results [34]. Early administration of empirical antibiotic therapy is recommended in VAP. VAP is the main cause of antibiotic use in ICUs. The rate of VAP reaches up to $40 \%$ for brain-injured patients hospitalized in the ICU [7]. Rather than using a combination of CRP, procalcitonin, or other biomarkers plus clinical criteria, the clinical practice guidelines by the Infectious 
Diseases Society of America and the American Thoracic Society recommend using the clinical criteria of disease alone in deciding whether or not to initiate antibiotic therapy [35]. For patients with VAP, a 7-day course of antimicrobial therapy is recommended [35]. The result from the present pilot study indicates that using the index test could with a sensitivity and specificity $>90 \%$ identify the patients with VAP and therefore motivate a shorter course of antibiotic therapy using smaller spectrum antibiotics.

More than $30 \%$ of nosocomial infections comprise urinary tract infections. The origin of nosocomial bacteria is endogenous (the patient's flora) in two-thirds of cases. Patients with indwelling urinary catheters are at high risk of developing nosocomial infections, especially urinary tract infections [36]. In this present study on patients receiving antibiotic prophylaxis and febrile patients with heavy empirical antibiotic therapy, data about nosocomial urinary tract infections were not reliable and the index test was positive in patients in which it is not possible to confirm or rule out the disease. The cutoff test used [37] was not appropriate for urine samples.

Based on the clinical guidelines and due to severe complications of delayed therapy, empirical antibiotic treatment is recommended in patients who develop fever post-neurosurgery. In this study, $64 \%$ of patients who underwent neurosurgery at our department received empirical therapy against nosocomial CNS infection with high doses of broad-spectrum antibiotics. Of the total 117 patients included in the study, only 7 patients $(0.06 \%)$ did not receive antibiotics. However, we observed that 19 patients $(16 \%)$ had a confirmed CNS infection and 32 patients (27\%) had VAP. These findings indicate the value of screening tests in distinguishing the site of infection and ruling out the most severe CNS infection long before the culture results are available.

This study has a limitation. It has only provided indirect evidence that the index test can result in the decrease in inappropriate use of antibiotics. The results of this work should be confirmed in multicenter prospective studies using the results from the pilot study to calculate the patient size and power.

\section{Conclusions}

The local production of injured organ cells and activated leukocytes during an unspecific immune reaction was used to construct a test platform for locating the site of infection in febrile patients who had undergone neurosurgery. The study revealed that this rapid screening test could identify the site of infection with clinically relevant sensitivity and specificity, indicating its potential to minimize the unnecessary use of antibiotics. If our primary results are confirmed through independent multicenter prospective studies, we will have access to a tool to guide antibiotic therapy and save resources even in non-equipped centers where the misuse of antibiotics is most rampant.

\section{Abbreviations}

NETs: Neutrophil extracellular traps

DNA: deoxyribonucleic acid 
VAP: Ventilator-associated pneumonia

IDSA: Infectious Diseases Society of America

CSF: Cerebrospinal fluid

CRP: C-reactive protein

PMA: Phorbol myristate acetate

IL-8: Interleukin 8

LPS: Lipopolysaccharide

ICU: Intensive Care Unit

CNS: Central Nervous System

\section{Declarations}

\section{- Ethics approval and consent to participate}

The study results were based on analysis of unidentifiable left-over samples collected within few hours after sampling by a nurse in coded tubes. No consent for publication (written or verbal) was necessary. The ethical committee of Linköping University Hospital approved this study (2010/284-32, 2015/429-32). Please see even the Guidance on Informed Consent for In Vitro Diagnostic Device Studies Using Leftover Human Specimen (https://www.fda.gov). The study has been registered on clinicaltrials.gov (NCT03252028).

\section{- Consent for publication}

- Not applicable.

Availability of data and materials

The datasets used and/or analyzed during the current study are available from the corresponding author on reasonable request.

Competing interests

Fariba Nayeri is the founder of PEAS Institute. PEAS Institute has filed a patent application for the presented platform. The other authors have no competing interests. 


\section{Funding}

The study is a part of PhD thesis at the Department of Neurology, University Hospital in Linköping. ALF grant is the abbreviation of an agreement between national government and seven regions in Sweden. The agreement regulates, among other things, the amount of government funds the region receive for participating in the education and training of doctors, implementing clinical research and developing health and medical care. The funds are disbursed by the Ministry of Education and Research (https://www.vr.se). The study was economically supported by ALF grants (LiO-611331, LiO-698931).

\section{Authors' contributions}

AM participated in design of study and carried out the studies on samples and analysis of data and drafted the manuscript. RD studied the neutrophils and production of NETs in CSF during bacterial meningitis and participated in laboratory analysis and drafted the manuscript. LE participated in the conception and design of the study, interpretation of results and designed the in-house reader and drafted the manuscript. JL participated in the design of the study and performed the statistical analysis. LY participated in sample analysis and laboratory analysis, FN participated in study design and coordination and drafted the manuscript. AT participated in design of study, supervising and coordination of study, analysis of data and drafted the manuscript. FN and AT share the last author position. All authors read and approved the final manuscript.

\section{Acknowledgments}

We are grateful to Tayeb Nayeri, who hypothesized and developed the platform, to the staff at the neurosurgical ICU of Linköping University Hospital for helping with sample collection, and to Sepahdar Mansouri for the management and laboratory assistance.

\section{Authors' information}

${ }^{1}$ Division of Neuro and Inflammation Science, Department of Clinical and Experimental Medicine, Linköping University, Department of Neurosurgery, Anesthetics Operations and Specialty Surgery Center, Region Östergötland, Sweden.

2 Department of Dental Research, Malmö University, Sweden

3 The Institute for Protein Environmental Affınity Surveys (PEAS Institute), Linköping, Sweden

${ }^{4}$ Foundation for Clinical and Experimental Science, Beryll, Linköping, Sweden

\section{References}


1. Peterson JW. Bacterial pathogenesis. In: Medical Microbiology, 4th Ed, The University of Texas Medical Branch at Galveston: Galveston, TX. 1996;Chapter 7.

2. Tunkel AR, Hartman BJ, Kaplan SL, Kaufman BA, Roos KL; Scheld M, Whiteley RJ. Practise guidelines for the management of bacterial meningitis. Clinical Infectious Diseases. 2004; 39(9):1267-1284.

3. Infectious Diseases Society of America (IDSA). Combating antimicrobial resistance: Policy recommendations to save lives. Clinical Infectious Diseases. 2011;52(S5):397-428.

4. Pechere JC, Hughes D, Kardas P, Cornaglia G. Non-compliance with antibiotic therapy for acute community infections: a global survey. International journal of Antimicrobial Agents. 2007;29(3):245253.

5. Baur D, Gladstone BP, Burkert F, Carrara E, Foschi F, Döbele S, et al: Effect of antibiotic stewardship on the incidence of infection and colonisation with antibiotic-resistant bacteria and Clostridium difficile infection: a systematic review and meta-analysis. Lancet Infect Dis. 2017;17(9):990-1001.

6. Vande Beek D, Drake JM, Tunkel AR: Nosocomial Bacterial Meningitis. N Engl J Med 362.2010;362(2):146-54.

7. Roquilly A, Feuillet F, Seguin P, Lasocki S, Cinotti R, Launey $Y$, et al: Empiric antimicrobial therapy for ventilator-associated pneumonia after brain injury. Eur Respir J. 2016;47(4):1219-28.

8. Schade RP, Schinkel J, Roelandse FWC, Geskus RB, Visser LG, van Dijk JMC, et al: Lack of value of routine analysis of cerebrospinal fluid for prediction and diagnosis of external drainage-related bacterial meningitis. J Neurosurg. 2006;104(1):101-8.

9. Newman B, Krane EJ, Gawande R, Holmes TH, Robinson TE: Chest CT in children: anesthesia and atelectasis. Pediatr Radiol. 2014;44:164- 172.

10. Kim B-N, Choi S-I, Ryoo N-H: Three-Year Follow-up of an Outbreak of Serratia marcescens Bacteriuria in a Neurosurgical Intensive Care Unit. J Korean Med Sci. 2006;21:973-978.

11. Nathan BR, Scheld WM: The potential roles of C-reactive protein and procalcitonin concentrations in the serum and cerebrospinal fluid in the diagnosis of bacterial meningitis. Curr Clin Top Infect Dis. 2002;22:155-65.

12. Wu C, Nakka S, Mansouri S, Bengtsson T, Nayeri T, Nayeri F: In vitro model of production of antibodies; a new approach to reveal the presence of key bacteria in polymicrobial environments. BMC Microbiol 16:2016 Available:

13. Domenech M, Ramos-Sevillano E, García E, Moscoso M, Yuste J: Biofilm Formation Avoids Complement Immunity and Phagocytosis of Streptococcus pneumoniae. Infect Immun 81. 2013;81(7):2606-2615.

14. Sollberger G, Tilley DO, Zychlinsky A: Neutrophil Extracellular Traps: The Biology of Chromatin Externalization. Dev Cell 44.2018;44(5):542-553.

15. Brinkmann V, Ulrike R, Christian G, Beatrix F, Yvonne U, David S. W, Yvette W, Arturo Z. "Neutrophil Extracellular Traps Kill Bacteria". Science. 2004; 303 (5663): 1532-1535. 
16. Thomas MP, Whangbo J, McCrossan G, J.Deutsch A, Martinod K,Walch M,et al. Leukocyte protease binding to nucleic acids promotes nuclear localization and cleavage of nucleic acid binding proteins. Journal of Immunology.2014; 192 (11): 5390-7.

17. Jorch SK, KubesP. An emerging role for neutrophil extracellular traps in noninfectious disease. Nature Medicine. 2017;23 (3): 279-287.

18. Yang $\mathrm{H}$, Biermann MH, Brauner JM, Liu Y, Zhao Y, Herrmann M. New Insights into Neutrophil Extracellular Traps: Mechanisms of Formation and Role in Inflammation. Frontiers in Immunology. 2016;7:302.

19. Urban C.F, Ermert D, Schmid M, Abu-Abed U, Goosmann C, Nacken W, et al. Neutrophil extracellular traps contain calprotectin, a cytosolic protein complex involved in host defense against Candida albicans. PLoS Pathog. 2009;5(10):e1000639.

20. Ramezani A, Alipouratigh M, Eng L, Turkina MV, Lönn J, Theodorsson A, et al: One-minute through test to distinguish lower respiratory infection by analysis of sputum; exploring the mechanisms. BMC Res Notes. 2018;11(1):664.

21. Bergeron JA, Singer M. Metachromasy: an experimental and theoretical reevaluation. J Biophys Biochem Cytol.1958; 4(4):433-57.

22. Pham NA, Morrison A, Schwock J, AvielRonen S, lakovlev V, Tsao MS, et al. Quantitative image analysis of immunohistochemical stains using a CMYK color model, Diagn Pathol Pathol,2007;2:8.

23. Rosner B: Fundamentals of Biostatistics.7th ed., Boston:Brooks/Cole,Cengage Learning,2011.

24. The management of neurosurgical patients with postoperative bacterial or aseptic meningitis or external ventricular drain-associated ventriculitis. Infection in Neurosurgery Working Party of the British Society for Antimicrobial Chemotherapy. Br J Neurosurg. 2000;14(1):7-12.

25. McClelland S, Hall WA. Postoperative Central Nervous System Infection: Incidence and Associated Factors in 2111 Neurosurgical Procedures. Clin Infect Dis.2007; 45(1):55-59.

26. Conen A, Walti LN, Merlo A, Fluckiger U, Battegay M, Trampuz A: Characteristics and Treatment Outcome of Cerebrospinal Fluid Shunt-Associated Infections in Adults: A Retrospective Analysis over an 11-Year Period. Clin Infect Dis. 2008;47(1):73-82.

27. Lozier AP, Sciacca RR, Romagnoli MF, Connolly ES: Ventriculostomy-related infections. Neurosurgery.2002;51(1):170-81.

28. Governale LS, Fein N, Logsdon J, Black PM: Techniques and complications of external lumbar drainage for normal pressure hydrocephalus: Oper Neurosurg. 2008;63(4 Suppl 2):379-84.

29. Baltas I, Tsoulfa S, Sakellariou P, Vogas V, Fylaktakis M, Kondodimou A: Posttraumatic meningitis: bacteriology, hydrocephalus, and outcome. Neurosurgery. 1994;35(3):422-6

30. Adriani KS, van de Beek D, Brouwer MC, Spanjaard L, de Gans J: Community-Acquired Recurrent Bacterial Meningitis in Adults. Clin Infect Dis.2007;45(5):e46-51.

31. Leib SL, Boscacci R, Gratzl O, Zimmerli W: Predictive Value of Cerebrospinal Fluid (CSF) Lactate Level Versus CSF/Blood Glucose Ratio for the Diagnosis of Bacterial Meningitis Following 
Neurosurgery. Clin Infect Dis.1999;29(1):69-74.

32. Soavi L, Rosina M, Stefini R, Fratianni A, Cadeo B, Magri S, et al: Post-neurosurgical meningitis: Management of cerebrospinal fluid drainage catheters influences the evolution of infection. Surg Neurol Int.2016;7(Suppl 39):S927-S934.

33. Mandell GL, Douglas RG, Bennett JE, Dolin R. Mandell, Douglas, and Bennett's Principles and Practice of Infectious Diseases.6th ed., New York: Elsevier/Churchill Livingstone, 2005.

34. Hassinger T, Sawyer R: Should We Immediately Start Antibiotics in Every Patient with a Clinical Suspicion of HAP/VAP? Semin Respir Crit Care Med. 2017;38(3):245-252.

35. Kalil AC, Metersky ML, Klompas M, Muscedere J, Sweeney DA, Palmer LB, et al: Executive Summary: Management of Adults With Hospital-acquired and Ventilator-associated Pneumonia: 2016 Clinical Practice Guidelines by the Infectious Diseases Society of America and the American Thoracic Society. Clin Infect Dis. 2016;63(5):e61-e111.

36. Iacovelli V, Gaziev G, Topazio L, Bove P, Vespasiani G, Finazzi Agrò E: Nosocomial urinary tract infections: A review. Urologia.2014;81(4):222-7.

37. Ramezani A, Eng L, Turkina MV, Theodorsson A, Nayeri F: A Sputum Screening Test to Rule Out Pneumonia at an Early Stage With High Negative Predictive Value: Point Care J -Patient Test Technol.2018;17:101-108.

\section{Tables}




\begin{tabular}{|c|c|c|c|c|c|c|c|c|c|c|}
\hline sex & age & $\begin{array}{l}\text { dExact } \\
\text { CSF }\end{array}$ & $\begin{array}{l}\text { dExact } \\
\text { urine }\end{array}$ & $\begin{array}{l}\text { dExact } \\
\text { bronchial } \\
\text { fluid }\end{array}$ & $\begin{array}{l}\text { CRP } \\
\mathrm{mg} / \mathrm{L}\end{array}$ & $\begin{array}{l}\text { PCT } \\
\mu \mathrm{g} / \mathrm{L}\end{array}$ & $\begin{array}{l}\text { CSF WBC } \\
\times 10^{9}\end{array}$ & \begin{tabular}{|l|} 
CSF \\
Poly \\
$\mathbf{x}$ \\
$10^{9}$ \\
\end{tabular} & $\begin{array}{l}\mathrm{CSF} \\
\text { lactate } \\
\mathrm{mmol} / \mathrm{L}\end{array}$ & $\begin{array}{l}\text { Microbiologic } \\
\text { assessments }\end{array}$ \\
\hline M & 87 & pos & pos & neg & 133 & 0.1 & 3840 & 3680 & 9.8 & neg \\
\hline $\bar{M}$ & 76 & pos & nd & nd & 99 & 3.5 & 346 & 188 & 4.4 & $\begin{array}{l}\text { Streptococcus } \\
\text { pneumoniae }\end{array}$ \\
\hline $\bar{F}$ & 69 & pos & pos & neg & 20 & 0.1 & 8.8 & 0 & 3.4 & $\begin{array}{l}\text { Staphylococcus. } \\
\text { aureus }\end{array}$ \\
\hline $\bar{F}$ & 71 & neg & nd & nd & 117 & 0.1 & 385 & 215 & 7.9 & $\begin{array}{l}\text { Staphylococcus. } \\
\text { aureus }\end{array}$ \\
\hline $\mathrm{M}$ & 70 & pos & pos & neg & 260 & 8.0 & 12.2 & 0.6 & 6.5 & Escherichia coli \\
\hline M & 68 & pos & pos & neg & 38 & 0.1 & 21.4 & 0.6 & 2.1 & $\begin{array}{l}\text { Propionibacterium } \\
\text { acnes }\end{array}$ \\
\hline $\mathrm{F}$ & 69 & neg & neg & neg & 423 & 3.3 & 281 & 67 & 3.2 & neg (visible pus) \\
\hline $\mathrm{M}$ & 69 & pos & nd & nd & 5 & 0.1 & 25.8 & 3 & 2.8 & neg (visible pus) \\
\hline $\bar{F}$ & 65 & pos & nd & nd & 198 & 0.4 & 2.5 & 0.5 & 3.3 & $\begin{array}{l}\text { Propionibacterium } \\
\text { acnes }\end{array}$ \\
\hline $\mathrm{M}$ & 62 & pos & pos & neg & 5 & 0.1 & 2.8 & 0 & 2.1 & Toxoplasmosis \\
\hline $\bar{F}$ & 61 & pos & pos & pos & 40 & 0.1 & 8640 & 4080 & 3.1 & $\begin{array}{l}\text { alpha } \\
\text { streptococcus }\end{array}$ \\
\hline $\bar{F}$ & 60 & pos & neg & nd & 14 & 0.1 & 9.7 & 2.5 & 2.3 & $\begin{array}{l}\text { Staphylococcus } \\
\text { epidermidis }\end{array}$ \\
\hline $\bar{F}$ & 50 & pos & nd & nd & 136 & 0.2 & 974 & 916 & 6.8 & $\begin{array}{l}\text { Enterobacter } \\
\text { cloacae }\end{array}$ \\
\hline $\mathrm{M}$ & 48 & pos & pos & pos & 273 & 13 & 1295 & 1095 & 5.4 & $\begin{array}{l}\text { Streptococcus } \\
\text { pneumoniae }\end{array}$ \\
\hline $\mathrm{M}$ & 48 & pos & neg & neg & 192 & 0.2 & 257.5 & 130 & 4.4 & $\begin{array}{l}\text { Staphylococcus } \\
\text { epidermidis }\end{array}$ \\
\hline $\bar{F}$ & 40 & pos & pos & neg & 34 & 0.1 & 6.5 & 2.6 & 2.1 & $\begin{array}{l}\text { Propionibacterium } \\
\text { acnes }\end{array}$ \\
\hline $\mathrm{M}$ & 36 & pos & pos & pos & 131 & 0.2 & 1950 & 1716 & 3.3 & Achromobacter \\
\hline $\bar{M}$ & 15 & pos & neg & neg & 11 & 0.1 & 295 & 5 & 6.5 & $\begin{array}{l}\text { alpha } \\
\text { streptococcus }\end{array}$ \\
\hline $\bar{M}$ & 1 & pos & neg & nd & 161 & 0.5 & na & na & na & $\begin{array}{l}\text { Streptococcus } \\
\text { pneumoniae }\end{array}$ \\
\hline
\end{tabular}

Table 1: The diagnosis of CNS infection was verified in 19 cases. $F=$ female, $M=$ male neg= negative, pos= positive, nd= non-defined, na=not available 
Page 16/20 


\begin{tabular}{|c|c|c|c|c|c|c|c|c|c|}
\hline $\operatorname{sex}$ & age & $\begin{array}{c}\text { Index } \\
\text { CSF }\end{array}$ & $\begin{array}{l}\text { Index } \\
\text { urine }\end{array}$ & $\begin{array}{l}\text { Index } \\
\text { lung }\end{array}$ & CRP & $\overline{\text { PCT }}$ & $\begin{array}{l}\text { CSF } \\
\text { LPK }\end{array}$ & $\begin{array}{c}\text { CSF } \\
\text { lactate }\end{array}$ & $\begin{array}{l}\text { Culture from } \\
\text { bronchial secretion }\end{array}$ \\
\hline $\mathrm{M}$ & 80 & neg & pos & pos & 61 & 0.8 & 231 & 5.2 & $n e g$ \\
\hline $\bar{F}$ & 78 & neg & pos & pos & 122 & 0.1 & 168 & 3.8 & neg \\
\hline $\mathrm{F}$ & 73 & neg & pos & pos & 87 & 0.2 & 11.3 & 3.3 & $\begin{array}{l}\text { Streptococcus } \\
\text { pyogenes }+ \\
\text { Corynebacterium }\end{array}$ \\
\hline $\mathrm{M}$ & 70 & neg & pos & pos & 41 & nd & 270 & 2.8 & neg \\
\hline $\bar{F}$ & 68 & pos & pos & pos & 270 & 0.3 & 565 & 3.4 & $\begin{array}{l}\text { Hemophylus } \\
\text { influenzae neg }\end{array}$ \\
\hline $\mathrm{M}$ & 68 & neg & pos & pos & 32 & 0.1 & 12.2 & 2.1 & $\begin{array}{l}\text { Hemophylus } \\
\text { influenzae }\end{array}$ \\
\hline $\bar{F}$ & 68 & neg & neg & pos & 132 & 0.3 & 6 & 3.2 & $\begin{array}{l}\text { Proteus mirabilis }+ \\
\text { Serratia marcenses }\end{array}$ \\
\hline$M$ & 68 & neg & nd & nd & 44 & 0.2 & 8.9 & 3.1 & Klebsiella \\
\hline $\bar{F}$ & 66 & pos & pos & pos & 27 & 0.1 & 67.5 & 2.5 & $\begin{array}{l}\text { Neisseria } \\
\text { flavenscens }\end{array}$ \\
\hline $\bar{F}$ & 65 & neg & neg & pos & 169 & 0.6 & 20 & 2.6 & neg \\
\hline $\bar{M}$ & 65 & pos & pos & pos & 114 & 0.1 & 660 & 3.2 & $\begin{array}{l}\text { Enterobakter }+ \\
\text { Hemophylus } \\
\text { influenza }\end{array}$ \\
\hline $\bar{M}$ & 65 & neg & neg & nd & 173 & 0.1 & 16.3 & 2.5 & $\begin{array}{l}\text { Pseudomonas } \\
\text { aeroginosa }\end{array}$ \\
\hline $\mathrm{M}$ & 64 & pos & pos & pos & 243 & 0.6 & 6.4 & 2.9 & neg \\
\hline $\bar{M}$ & 64 & neg & pos & neg & 173 & 0.5 & 117 & 5.2 & $\begin{array}{l}\text { Staphylococcus } \\
\text { aureus }\end{array}$ \\
\hline $\bar{M}$ & 63 & neg & pos & pos & 347 & 3.9 & 37.5 & 3.3 & $\begin{array}{l}\text { Alpha Streptococker } \\
+ \text { citerobacter }\end{array}$ \\
\hline $\mathrm{F}$ & 62 & neg & pos & pos & 49 & 0.1 & 5.4 & 2.2 & Enterococcus fecalis \\
\hline $\mathrm{F}$ & 61 & neg & neg & pos & 102 & 1.3 & 19 & 4.0 & neg \\
\hline $\mathrm{M}$ & 63 & neg & pos & pos & 80 & 0.2 & 305 & 4.7 & neg \\
\hline $\mathrm{F}$ & 62 & neg & nd & pos & 28 & 0.1 & 1.9 & 2.9 & $\begin{array}{l}\text { Pasturella canis + } \\
\text { Escherichia coli }\end{array}$ \\
\hline $\bar{F}$ & 59 & neg & nd & pos & 28 & 0.1 & 37 & 4.0 & $\begin{array}{l}\text { Moraxella } \\
\text { catarrhalis }\end{array}$ \\
\hline $\bar{F}$ & 60 & neg & neg & pos & 10 & 0.1 & 129.4 & 4.3 & neg \\
\hline $\bar{F}$ & 57 & neg & pos & pos & 180 & 2.1 & na & 3.8 & neg \\
\hline$\overline{\mathrm{F}}$ & 54 & neg & nd & nd & 101 & 0.1 & 40.8 & 3.1 & $\begin{array}{l}\text { Staphylococcus } \\
\text { aureus }\end{array}$ \\
\hline $\mathrm{M}$ & 54 & neg & nd & pos & 72 & 0.8 & na & na & $\begin{array}{l}\text { Staphylococcus } \\
\text { aureus }\end{array}$ \\
\hline $\mathrm{M}$ & 55 & neg & nd & pos & 28 & ej & 61 & 3.8 & $\begin{array}{l}\text { Streptococcus } \\
\text { pneumonae + } \\
\text { Hemophylus } \\
\text { influenzae }\end{array}$ \\
\hline $\mathrm{M}$ & 53 & neg & pos & pos & 154 & 0.4 & 1.4 & 4.0 & neg \\
\hline $\mathrm{F}$ & 52 & neg & neg & pos & 127 & 0.3 & 1.0 & 1.7 & $\begin{array}{l}\text { Hemophylus } \\
\text { influenzae }\end{array}$ \\
\hline $\mathrm{M}$ & 43 & neg & pos & pos & 74 & 0.2 & 160 & 4.4 & Alpha Streptococker \\
\hline $\bar{M}$ & 42 & neg & pos & pos & 136 & 0.2 & 77 & 3.5 & $\begin{array}{l}\text { Hemophylus } \\
\text { influenza }\end{array}$ \\
\hline $\mathrm{M}$ & 40 & neg & neg & pos & 127 & 0.1 & 3.9 & 1.9 & $\begin{array}{l}\text { Hemophylus } \\
\text { Influenza }\end{array}$ \\
\hline $\mathrm{M}$ & 30 & neg & neg & pos & 81 & 0.1 & 0.6 & 1.6 & $\begin{array}{l}\text { Candida albicans }+ \\
\text { Candida dublinesis }\end{array}$ \\
\hline $\bar{F}$ & 39 & neg & neg & neg & 52 & 0.3 & na & 3.1 & neg \\
\hline $\bar{F}$ & 38 & pos & pos & pos & 138 & 0.4 & 155 & 2.1 & Klebsiella \\
\hline $\mathrm{M}$ & 33 & neg & nd & nd & 110 & 0.1 & 2.2 & 1.4 & Enterobacter + \\
\hline
\end{tabular}




\begin{tabular}{|l|l|l|l|l|l|l|l|l|l|} 
& & & & & & & & & $\begin{array}{l}\text { Staphylococcus } \\
\text { aureus }\end{array}$ \\
\hline M & 35 & neg & pos & pos & 272 & 0.6 & 6.9 & 4.0 & Serratia marcenses \\
\hline M & 25 & neg & nd & pos & 425 & 14.0 & 5.0 & 3.2 & neg \\
\hline M & 21 & neg & pos & pos & 115 & 13 & 5.6 & 2.1 & neg \\
\hline F & 20 & neg & nd & nd & 54 & 0.1 & 325 & 3.1 & $\begin{array}{l}\text { Pseudomonas } \\
\text { aeroginosa }+ \\
\text { Hemophylus } \\
\text { influenza }\end{array}$ \\
\hline
\end{tabular}

Table 2: The patients that had a verified diagnosis of pneumonia

\begin{tabular}{|c|c|c|c|c|c|}
\hline \multicolumn{6}{|c|}{ Central nervous system (CNS) infection } \\
\hline Index test & Present & $\mathbf{n}$ & Absent & $\mathbf{n}$ & Total \\
\hline $\begin{array}{l}\text { Positive } \\
\text { Verified diagnosis }\end{array}$ & True Positive & $a=17$ & False Positive & $\mathrm{C}=6$ & $a+c=23$ \\
\hline $\begin{array}{l}\text { Negative } \\
\text { (VAP, sepsis, other infections) }\end{array}$ & False Negative & $b=2$ & True Negative & $d=74$ & $b+d=76$ \\
\hline Total & & 19 & & 80 & 99 \\
\hline
\end{tabular}

Table 3: Analysis of the index dip-test ability to distinguish CNS infection (verified) shows 89.5\% sensitivity (95\% CI 66.9-98.7\%), 92.5\% specificity (95\% CI 84.4-97.2\%), 97.4\% negative predictive value (95\% CI 90.9-99.3\%) and 73.9\% positive predictive value (95\% CI 56.4-86.2\%). Accuracy was 91.9\%.

\begin{tabular}{|c|c|c|c|c|c|}
\hline \multicolumn{6}{|l|}{ Ventilator associated pneumonia (VAP) } \\
\hline Index test & Present & $\mathbf{n}$ & Absent & $\mathbf{n}$ & Total \\
\hline Positive & True Positive & $a=30$ & False Positive & $\mathrm{C}=5$ & $a+c=35$ \\
\hline $\begin{array}{l}\text { Negative } \\
\text { (Meningitis, sepsis, other infection) }\end{array}$ & False Negative & $b=2$ & True Negative & $d=33$ & $\mathrm{~b}+\mathrm{d}=35$ \\
\hline Total & & 32 & & 38 & 70 \\
\hline
\end{tabular}

Table 4: Analysis of the index dip-test ability to distinguish respiratory infection shows 93.75\% sensitivity (95\% CI 79.2-99.2\%), 86.8\% specificity (95\% CI 71.9-95.6\%), 94.3\% negative predictive value (95\% CI 81.1-98.5\%) and 90\% positive predictive value (95\% CI 80.5-95.9\%). Accuracy was 90.0\%. 
Figures

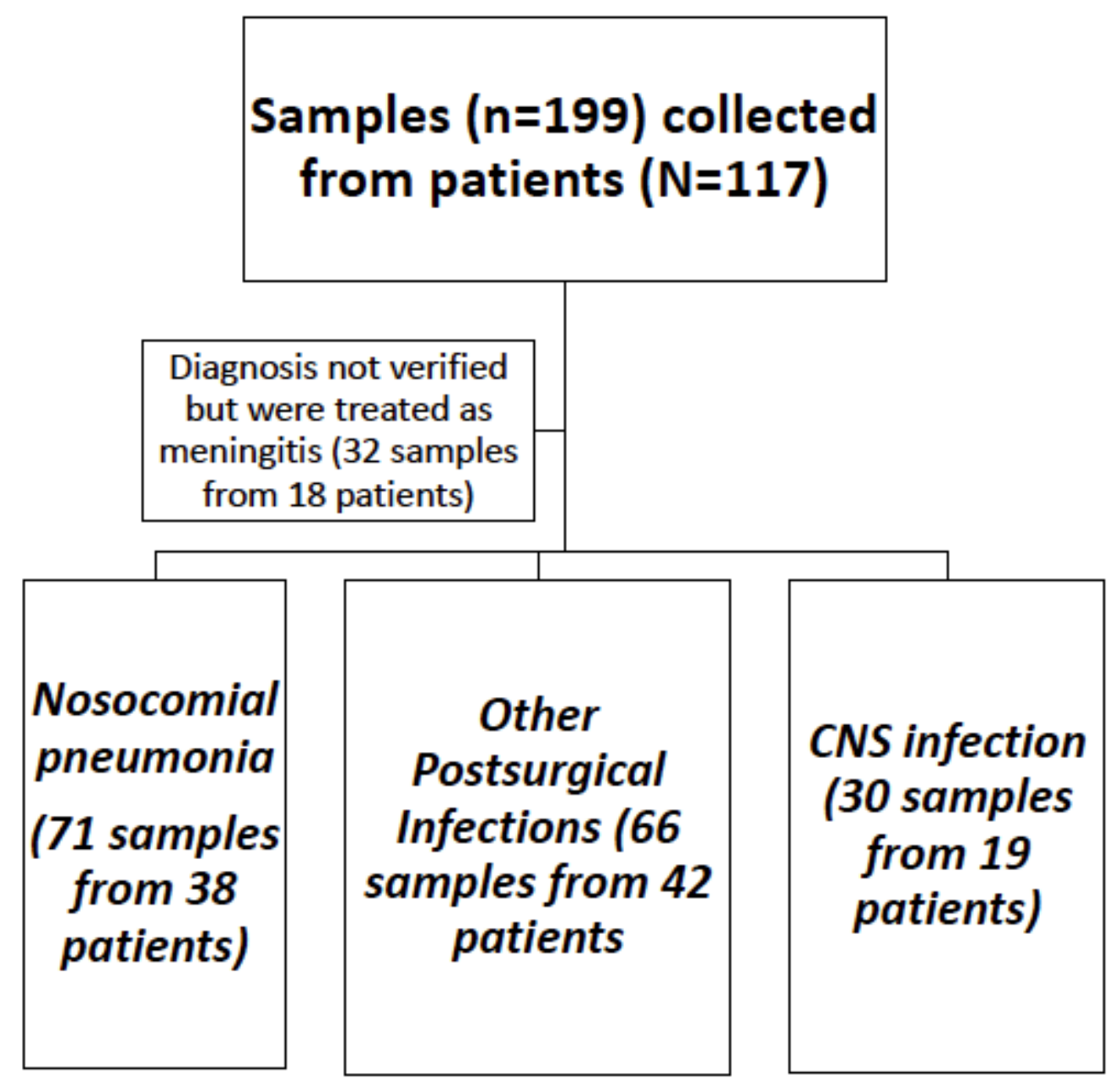

Figure 1

Flowchart of the study samples. CNS, central nervous system. 

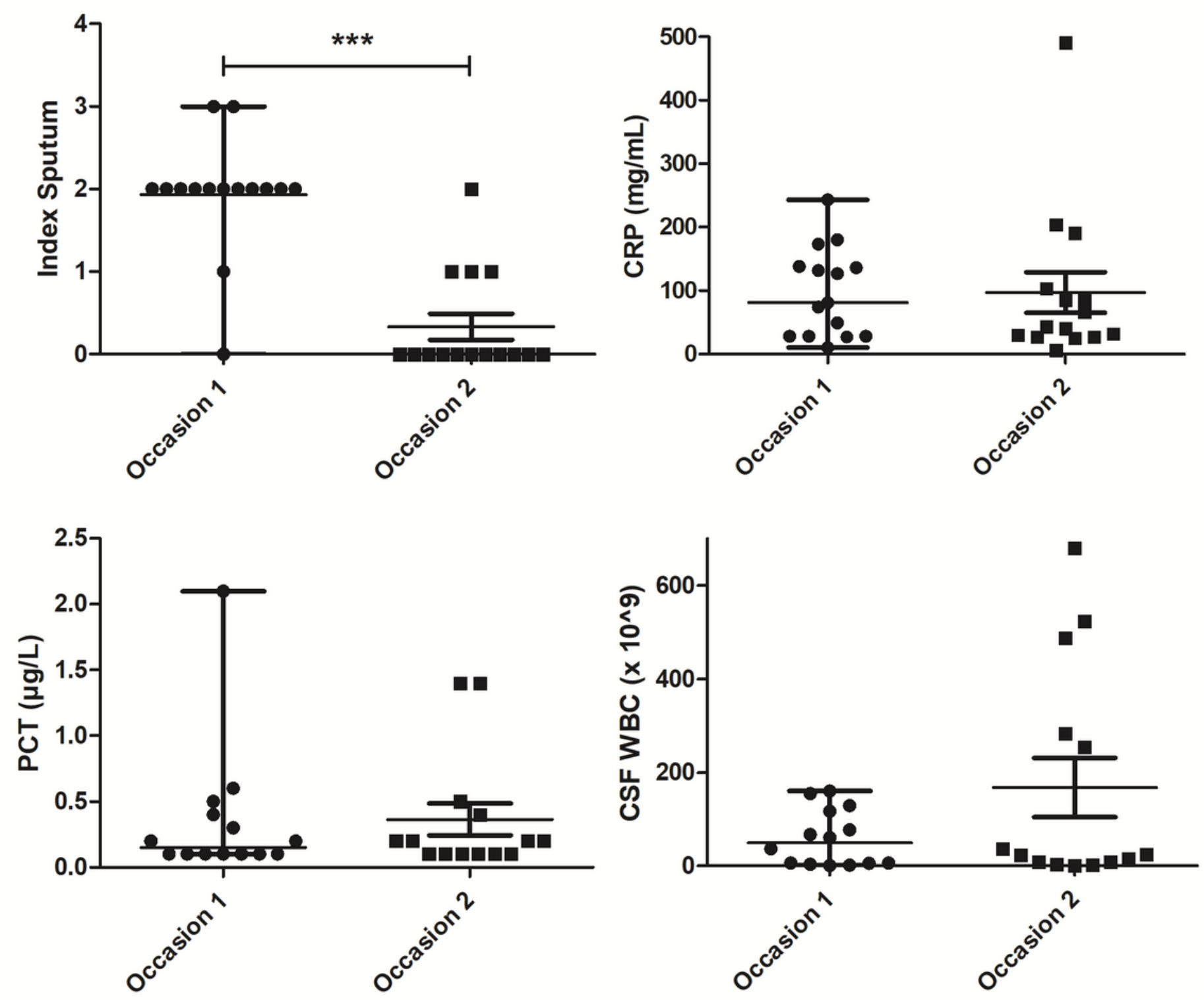

Figure 2

In 19 cases, two to six samples were collected on different occasions during the patients' stay in the ward. There were significant differences between the index test results before (Occasion 1) and after (Occasion 2) antibiotic therapy in this group.

\section{Supplementary Files}

This is a list of supplementary files associated with this preprint. Click to download.

- SupplementaryMaterials.docx 